\title{
URGENSI PENJAMINAN MUTU SEKOLAH
}

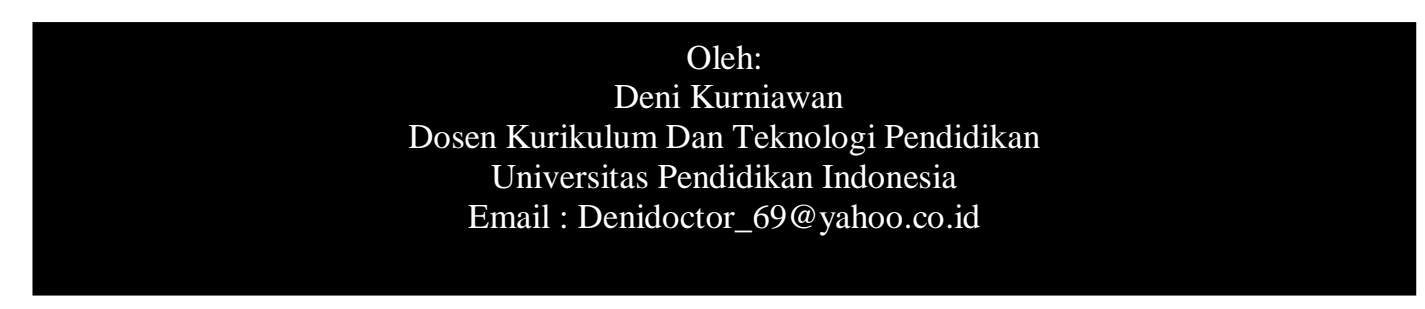

\begin{abstract}
, human resources have a central role in the development and advancement of an organization. Human recources development is closely related to educational institutions, one of which is school. In order to optimize the process education in schools, it is important to ensure school quality assurance system. The goal of this system is to fulfill the satisfaction of education stakeholders. To find out the expectations and satisfaction of the stakeholders, a school can obtain information by using various alternative ways deemed suitable with the kind of information expected and the resources owned by the school.
\end{abstract}

Keywords: quality assurance, satisfaction, stakeholders

Abstrak, sumber daya manusia memiliki peranan sentral bagi pengembangan dan kemajuan organisasi. Pengembangan SDM terkait erat dengan lembaga pendidikan, salah satunya adalah sekolah. Agar proses penyelenggaraan pendidikan di sekolah bisa optimal maka penting adanya sistem jaminan kualitas sekolah. Tujuan utama dari sistem jaminan kualitas sekolah adalah agar terpenuhinya kepuasan stakeholders pendidikan. Untuk mengungkap harapan dan kepuasan stakeholders sekolah bisa dilakukan melalui penggalian informasi dengan menggunakan beragam alternatif cara yang dipandang sesuai dengan jenis informasi yang diharapkan dan keberadaan sumber daya yang dimiliki sekolah.

Kata Kunci: jaminan kualitas, kepuasan, stakeholders,informasi

\section{A. PENDAhuluan}

Kualitas sumber daya manusia (SDM) merupakan komponen penting bagi kemajuan organisasi, baik organisasi yang besar menengah maupun kecil. SDM berkualitas akan mampu berperilaku aktif dan produktif sehingga akan menghasilkan kinerja yang baik. Hal ini telah dibuktikan oleh sejumlah penelitian atas beberapa negara maju di Eropa dan Amerika oleh Komisi Peningkatan Produktivitas yang dibentuk oleh Massachusset Institute of Technology (MIT), National Institute of Economic Review (NIER), dan penelitian Dornbusch dan fischer (1995).
Hasil studi MIT menunjukkan tingkat produktivitas bangsa Amerika lebih rendah dibandingkan negara Jepang dan Jerman diakibatkan oleh masyarakat Amerika, terutama pada lapisan menengah bawah, memiliki sifat lebih malas, ceroboh dan boros dibandingkan masyarakat Jepang dan Jerman. Sementra hasil studi NIER terhadap empat negara Eropa (Inggris, Jerman, Belanda, dan Perancis) menemukan fakta bahwa produktivitas bangsa Jerman lebih tinggi atas tiga negara Eropa lainnya yang diteliti disebabkan oleh kualitas SDM Jerman lebih tinggi dari tiga negara lainnya. 
Kemudian, hasil studi Dornbusch dan Fischer (1995) di Amerika Serikat menemukan fakta bahwa laju pertumbuhan GNP total sebesar 2,9\% per tahun, $0,32 \%$ disebabkan akumulasi modal; 1,09\% disebabkan produktivitas SDM; dan1,49\% lainnya oleh kemajuan teknologi (Ali; Kurniawan, 2004:1-2).

Data di atas menunjukkan bahwa peningkatan kualitas SDM merupakan hal yang sangat signifikan dan serius. Berbicara tentang peningkatan SDM maka tidak akan lepas dari pendidikan, dan bicara pendidikan tidak lepas dari lembaga pendidikannya itu sendiri, salah satunya adalah sekolah.

Sekolah sebagai r lembaga
pengembangan Sumber Daya Manusia
dituntut untuk mampu menghasilkan
output SDM yang berkualitas, maka
penyelenggaraan pendidikan di sekolah
harus punya orientasi pada kualitas. Salah
satu cara untuk mencapai hal ini adalah
dengan adanya sistem penjaminan kualitas
(mutu) sekolah. Untuk ini, seluruh stake
holder sekolah perlu memiliki pemahaman
dan kesadaran yang baik tentang
penjaminan mutu sekolah, untuk
selanjutnya mampu mewujudkan sekolah
yang bermutu.

\section{Rumusan Masalah}

a. Apa yang dimaksud dengan jaminan kualitas sekolah? b. Mengapa perlu ada jaminan kualitas sekolah?

c. Siapa sajakah yang menjadi pelanggan sekolah?

d. Faktor apakah yang menjadi indikator/penentu kepuasan pelanggan sekolah?

e. Bagaimanakah cara mengetahui kepuasan pelanggan sekolah?

\section{B. HASIL DAN PEMBAHASAN}

\section{Konsepsi jaminan kualitas} sekolah

\section{a. Konsepsi Kualitas}

Sebelum membahas lebih jauh apa jaminan kualitas, kita coba fahami terlebih dahulu apa itu kualitas. Berikut beberapa pengertian tentang mutu atau kualitas menurut beberapa lembaga dan ahli kualitas.

1. Menurut ISO 8402 (Quality Vocabulary) Kualitas didefinisikan sebagai totalitas dari karakteristik suatu produk menunjang kemampuan untuk memuaskan kebutuhan yang dispesifikasikan atau ditetapkan (Gaspersz, 2005).

2. Menurut American Society For Quality Control, mutu adalah totalitas bentuk dan karakteristik barang atau jasa yang menunjukkan kemampuannya untuk 
Edutech, Tahun 13, Vol.1, No.2, Juni 2014

kebutuhan-kebutuhan yang tampak jelas maupun tersembunyi.

3. Kemudian, A.V. Feigenbaum (1996; on line) menjelaskan bahwa mutu adalah keseluruhan karakteristik produk dan jasa dari pemasaran rekayasa, pembuatan dan pemeliharaan yang membuat produk dan jasa yang digunakan memenuhi harapan-harapan pelanggan (Feigenbaum, 1996).

Dari definisi-definisi di atas, bisa kita pahami bahwa pengertian mutu merujuk pada kesuaian produk yang dihasilkan dengan ketentuan jenis produk yang telah ditetapkan, kebutuhan terpenuhi, sehingga memberikan kepuasan pada pelanggan sebagai pengguna produk. Jadi, baik tidaknya suatu mutu produk dan jasa kriterianya adalah sejauh mana kepuasan pelanggan atau konsumen atas produk dan jasa yang diterimanya dari lembaga penghasil produk atau jasa tersebut.

Kualitas lebih ditentukan oleh pengguna produk/jasa bukan oleh masyarakat secara umum. Kualitas tidak berkaitan dengan biaya dan pernyataan kata sifat tinggi dan rendah. Sebagai contoh, produk yang dijual dengan harga murah bisa dipandang sebagai berkualitas tinggi karena produk ini mudah diopersikan, sebaliknya bisa produk yang berharga mahal bisa dikatakan memiliki kualitas yang rendah karena tidak bisa atau susah dioperasikan pemakai.

Agar produk dan jasa yang dihasilkan bisa memenuhi kualitas yang baik, maka perlu adanya sistem jaminan kualitas.

\section{b. Konsepsi Jaminan Kualitas}

Wikipedia, the free encyclopedia (tersedia: on line), menjelaskan Jaminan Kualitas (Quality assurance: $Q A$ ) menunjuk pada aktivitas rekayasa yang dilakukan pada sistem kualitas sehinga persyaratan atau spesifikasi produk atau jasa bisa terpenuhi. Aktivitas jaminan kualitas adalah kegiatan pengukuran yang sistematis, perbandingan produk yang dihasilkan dengan standar, monitoring proses dan terpadu dengan balikan (feed back) untuk mencegah terjadinya kesalahan.

Jaminan kualitas tidak sama dengan kontrol kualitas (quality control) dan Total Quality Management (TQM). Kontrol kualitas menekankan pada hasil 
Edutech, Tahun 13, Vol.1, No.2, Juni 2014

saja. Hal ini sejalan dengan penjelasan Freeman (1993; on line) ada dua prinsip utama dalam jaminan kualitas yaitu : 1) kesesuain dengan tujuan (Fit for purpose), produk yang dihasilkan harus sesuai dengan tujuan yang diharapkan. 2) Benar sejak awal (Right first time), kesalahan harus dihilangkan sejak awal proses. Jadi jaminan kualitas di dalamnya mencakup manajemen kualitas masukan, proses pengerjaan (assemblies), produk dan komponen-komponennya, layanan yang tekait dengan proses produksi, dan managemen produksi dan pengawasan proses.

Dalam konsep TQM menambahkan isu apakah biaya (cost) masuk kualitas ataukah tidak. Philosopinya adalah anda harus memperbaiki kualitas dengan sedikit menggunakan sumber daya, karena kalu tidak demikian, maka pesaing akan menang.

\section{c. Jaminan kualitas sekolah}

Freeman (1993; online) mendefinisikan Jaminan Kualitas sebagai pendekatan sistematis untuk mengindetifikasi kebutuhan pasar dan menentukan metode kerja untuk memenuhi kebutuhan pasar tersebut. Ketika konsep ini diterapkan pada sistem persekolahan yaitu dengan menekankan pada prinsip jaminan kualitas itu sendiri yaitu memenuhi kebutuhan pengguna (....meeting customer needs, are ones which are fully applicable in the new training and education markets).

Dengan merujuk pada penjelasan di atas, maka bisa kita fahami bahwa konsepsi jaminan kualitas dalam sistem persekolahan setidaknya merujuk pada :

1. Sejauh mana lulusan, sebagai keluaran hasil proses pendidikan, memenuhi harapan masyarakat (stake holders).

2. Untuk mencapai kualitas lulusan (out put) perlu adanya sistem dan prosedur penjaminan yang jelas proses penyelenggaraan pendidikan/pembelajaran di sekolah.

\section{d. Perlunya jaminan kualitas sekolah}

Mengapa sistem Jaminan Kualitas perlu, setidaknya baik diterapkan di sekolah? Berkaitan dengan pertanyaan ini Freeman (1993; on line) menjelaskan bahwa ide yang bagus untuk menerapkan Jaminan Kualitas di sekolah, dengan beberapa alasan : 
Edutech, Tahun 13, Vol.1, No.2, Juni 2014

1. misi dan tujuan sekolah menjadi jelas dan diketahui oleh semua pihak;

2. sistem kerja yang akan digunakan direncanakan secara baik dan dikomunikasi ke semua orang;

3. adanya kejelasan mengenai siapa yang bertanggung jawab atas apa;

4. adanya definisi kualitas yang jelas yang dipegang sekolah dan terdokumentasi dengan baik.

5. adanya sistem monitoring untuk mengecek segala hal berjalan sesuai rencana;

6. ketika terjadi kesalahan ada keinginan dan cara bisa yang digunakan untuk memperbaikinya secara jelas.

Lebih jauh Freeman (on line) menjelaskan, bahwa ada tiga hal penting yang harus ada dalam sistem Jaminan Kualitas di sekolah, yaitu:

1. Adanya metode pengecekan untuk mengetahui sejauh mana sistem dijalankan;

2. Adanya metode untuk memperbaiki kesalahan;

3. Adanya metode pengubahan sistem seandainya sistem yang berlaku sudah tidak efektif lagi atau kedaluwarsa.

\section{e. Pihak yang menjadi pelanggan sekolah}

Gasperz (1997) memberikan beberapa pernyataan berkaitan dengan pengertian pelanggan, yaitu :

1. Pelanggan adalah orang yang tidak tergantung kepada kita, tetapi kita yang tergantung padanya.

2. Pelanggan adalah orang yang membawa kita kepada keinginannya.

3. Tidak ada seorang pun yang pernah menang beradu argumentasi dengan pelanggan.

4. Pelanggan adalah orang yang teramat penting yang tidak dapat dihapuskan.

Dari beberapa definisi pelanggan di atas, maka dapat difahami bahwasanya palanggan adalah orang yang menggunakan jasa kita untuk memenuhi tuntutan kebutuhan mereka, dan kita membutuhkan mereka untuk dapat menjalankan lembaga atau badan yang kita kelola.

Selain dari pada itu, Muhaimin, et.all. (2009) menjelaskan bahwa pelanggan 
Edutech, Tahun 13, Vol.1, No.2, Juni 2014

(stakeholders) sekolah yaitu terdiri dari stakehloders primer, sekunder, dan tersier. Gambaran stakeholders sebagaimana dimaksud Muhaimin, et.all. tampak pada skema di halaman tujuh.

Mencermati skema tersebut, tampak bahwa stakeholder utama sekolah adalah siswa. Namun demikian, siswa datang ke sekolah karena adanya pembiayaan dari orang tua, sehingga komponen siswa dan orang tua adalah komponen yang paling harus diperhatikan. Hal ini sejalan dengan penjelasan Freeman (1993: online) bahwa yang menjadi pelanggan atau pengguna produk lembaga pendidikan dan pelatihan adalah siswa, orang tua, dan masyarakat pengguna lulusan. Dalam kaitan ini sekolah harus, mengidentifikasi kinerja penting apa yang mempengaruhi layanan sekolah menurut persepsi pengguna. Artinya sekolah harus menyediakan layanan terbaik untuk memenuhi harapan pelanggan.

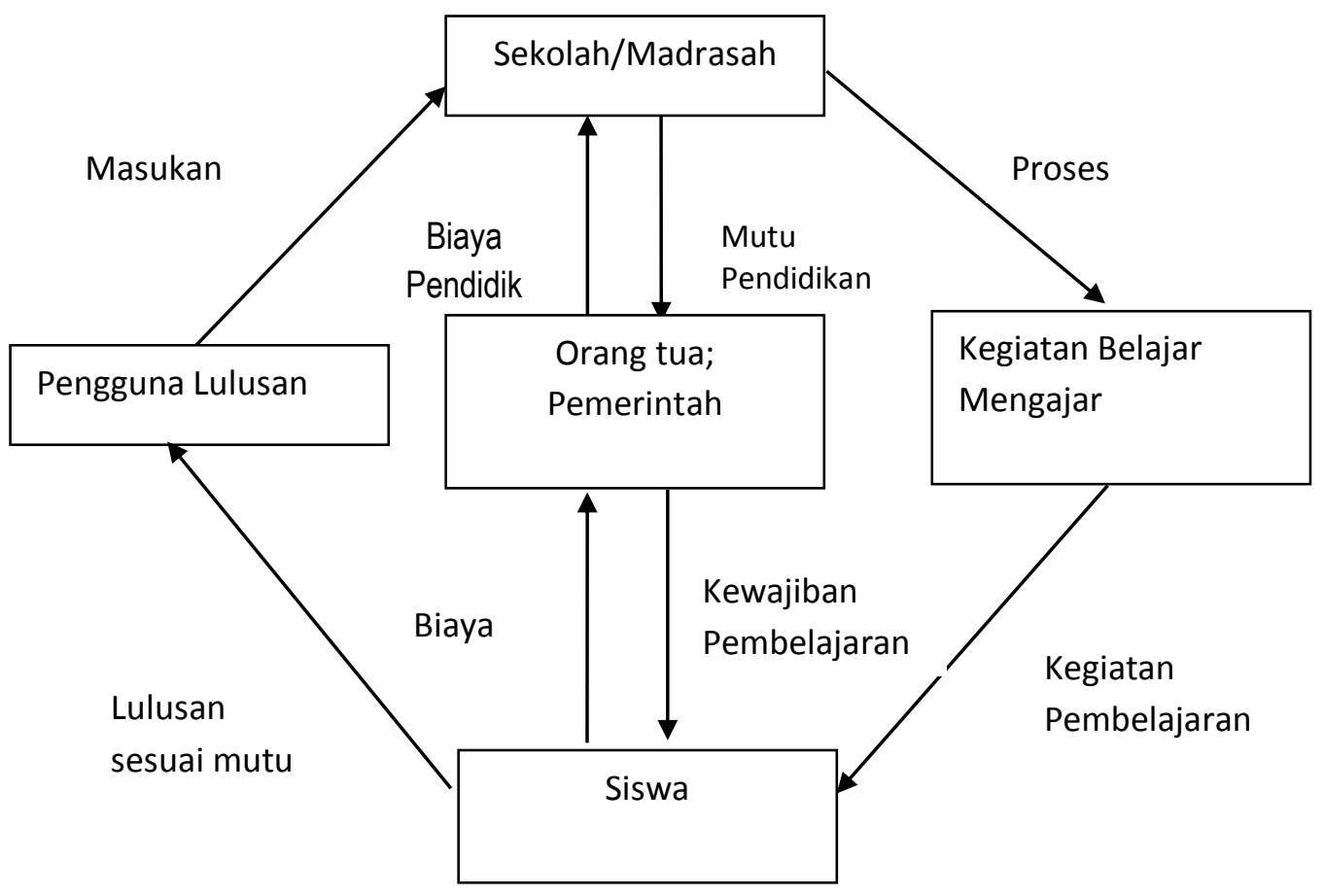

Gambar 1 . Skema stakeholders sekolah/Madrasah (Muhaimin, el.all. (2009:138)

Dengan demikian maka yang menjadi pelanggan utama sekolah Berikut hubungan konseptual adalah siswa, orang tua, dan antara harapan dengan kepuasan pengguna lulusan. 
Edutech, Tahun 13, Vol.1, No.2, Juni 2014

pelanggan, terutama untuk bidang jasa:

1. Makin dekat harapan jasa yang diharapkan pelanggan dengan jasa minimum yang dapat diterima oleh pelanggan, makin besar pula kemungkinan tercapainya kepuasan

2. Palanggan yang puas bisa berada di mana saja dalam spektrum ini. Yang menentukan adalah posisi hasil yang diharapkan.

Idealnya seluruh stakeholders dijadikan dasar untuk melaksanakan program jaminan kualitas sekolah, namun karena jaminan kualitas itu memerlukan kesiapan dan sumber daya pendukung yang memadai dengan kemampuan sumber daya yang dimiliki sekolah, sedangkan tidak semua sekolah memiliki sumber daya dibutuhkan, maka perlu ada prioritas stakeholder yang harus didahulukan

\section{f. Indikator penentu kepuasan pelanggan sekolah}

Pada dasarnya, karena jaminan kualitas sekolah mengacu pada kepuasan stakeholders sekolah, maka indikator umum yang bisa dijadikan pegangan adalah adanya kepuasan stakeholder/pelanggan. Mengutip penjelasan Tse dan Wilton (Nasution; online) menyatakan bahwa kepuasan atau ketidakpuasan pelanggan adalah respons pelanggan terhadap evaluasi ketidaksesuaian (diskormasi) yang dirasakan antara harapan sebelumnya (atau norma kinerja lainnya) dan kinerja aktual produk yang dirasakan setelah pemakaiannya. Sedangkan Kotler (Nasution; online) menyatakan bahwa kepuasan pelanggan adalah tingkat perasaan seseorang setelah membandingkan kinerja atau hasil yang ia rasakan dengan harapannya.

Idealnya semua stakeholder pendidikan dijadikan pedoman dalam penyusunan dan implementasi program jaminan kualitas sekolah. Namun karena pengembangan dan implementasi program jaminan kualitas sekolah ini berbanding lurus dengan keberadaan daya dukung dan kondisi sumber daya sekolah yang dimiliki, maka sekolah harus membuat skala prioritas sasaran jaminan kualitas sekolah. Dari paparan sebelumnya kita ketahui bahwa pelanggan (stake holders) 
Edutech, Tahun 13, Vol.1, No.2, Juni 2014

utama sekolah adalah siswa, orang tua, dan pengguna lulusan. Ketiga elemen stake holders tersebut apabila ingin digali informasinya untuk memenuhi kepuasan mereka banyak variabel yang bisa digali. Namun setidaknya bisa kita tentukan tiga variabel minimal utama jaminan kualitas sekolah yaitu:

1. sekolah menarik minat siswa

2. sekolah mendapatkan kepercayaaan masyarakat

3. sekolah mampu menghasilkan lulusan tepat guna.

\section{g. Cara mengetahui kepuasan pelanggan sekolah}

Untuk mengetahui sejauh mana kepuasan stakeholder sekolah atas pelayanan dan penyelenggaraan pendidikan yang diberikan, bisa dilakukan dengan beberapa teknik, diantaranya:

1. Survey kepuasan stakeholders

2. Studi harapan tentang harapan stakeholders atas layanan yang telah atau harus diberikan oleh sekolah, selanjutnya dibandingkan dengan layanan yang telah diberikan sekolah
3. Membuka program keluhan dan saran orang tua.

4. Studi dokumentasi atas data dan dokumen-dokumen yang menggambarkan kecenderungan kepuasan atas keterlibatan dalam proses pendidikan di sekolah.

5. Komentar-komentar atau catatan tentang peristiwaperistiwa yang berkaitan dengan sekolah.

6. Studi kepuasan pengguna lulusan, dan beberapa teknik penggalian informasi lainnya.

Adapun variabel yang perlu digali diantaranya:

1. Studi/Survey minat siswa: sikap, perilaku, perkembangan dan hubungan pribadi, kehadiran siswa dalam pembelajaran, pengerjaan tugas-tugas belajar, dan tingkat pencapaian standar kelulusan minimal. Selain itu, mungkin pula digali informasi tentang perkembangan spiritual, sosial, dan budaya.

2. Survey / studi kepercayaan masyarakat: harapan orang tua atas kesejahteraan/ 
kepedulian sekolah terhadap siswa, keamanan, kebijakan ujian, sistem bimbingan, pelibatan orang tua atas pembuatan kebijakankebijakan yang berkaitan dengan kesiswaan, pengembangan sekolah, dan yang lainnya.

3. Survey studi lulusan tepat guna: kemampuan kerja, sikap dalam bekerja kemampuan sosial, pengembangan diri,

kemampuan kerja sama dan lain-lain.

\section{SIMPULAN}

Pengembangan SDM berkaitan dengan lembaga pendidikan, salah satunya adalah sekolah. Agar sekolah bisa menyelenggarakan proses pendidikan secara optimal sehingga mampu menghasilkan out put yang bermutu baik maka penting adanya sistem jaminan kualitas sekolah. Pengertian kualitas merujuk pada kesuaian produk yang dihasilkan dengan ketentuan jenis produk yang telah ditetapkan, kebutuhan terpenuhi, sehingga memberikan kepuasan pada pelanggan sebagai pengguna produk. Adapun sistem jaminan kualitas sekolah adalah program sistematis dalam perencanaan, pelaksanaan, dan penilaian kualitas penyelenggaraan pendidikan di sekolah. Tujuan utama dari sistem jaminan kualitas sekolah adalah agar terpenuhinya kepuasan stakeholders pendidikan, terutama siswa, orang tua, dan pengguna lulusan. Untuk mengetahui sejauh mana atau bagaimana harapan para pelanggan sekolah harus dilakukan penggalian informasi mengenai harapan dan kepuasan pelanggan/stakeholders sekolah merupakan hal esensial dalam sistem jaminan kualitas sekolah. Penggalian informasi itu sendiri bisa menggunakan beragam alternatif teknik survey yang dipandang sesuai dengan jenis informasi yang diharapkan dan keberadaan sumber daya yang dimiliki sekolah. Setidaknya ada tiga variabel utama yang penting untuk diketahui melalui survey kepuasan pelanggan sekolah yaitu berkaitan dengan minat siswa, kepercayaan masyarakat, dan ketepatgunaan lulusan.

Melihat pentingnya jaminan kualitas sekolah untuk peningkatan kualitas sumber daya manusia, sudah selayaknya para pihak yang terkait dengan sistem penyelenggaraan sekolah memiliki pengetahuan dan kesadaran akan kualitas serta mengembangkan dan menerapkan sistem penjaminan kualitas di sekolahnya masing-masing.

\section{E. DAFTAR PUSTAKA}

Freeman ., (1993). Tersedia : on line.

Gasperssz, V., (1997). Manajemen Bisnis

Total dalam Era Globalisasi.

Jakarta: Gramedia Pustaka Utama. 
Edutech, Tahun 13, Vol.1, No.2, Juni 2014

Kurniawan, D., (2004). Profil Guru

Profesional di Sekolah Dasar

Berdasarkan Penilaian siswa,

Teman Sejawat, dan Masyarakat.

Bandung: Tesis UPI tidak

diterbitkan.

Muhaimin, et.all., (2009). Manajemen

Pendidikan - Aplikasinya dalam

Rencana Pengembangan

Sekolah/Madrasah. Jakarta:

Kencana Prenada Media.

Nasution nn., ( ). Konsep dan Prinsip

Sistem Penjaminan Mutu

Pendidikan. Tersedia:

http://mifoelum.students.uii.ac.id/20

13/04/01/konsep-dan-prinsip-sistem-

penjaminan-mutu-pendidikan/a

Noviyanto, D., (2011). Konsep Kepuasan

Pelanggan dalam Manajemen Mutu
Pendidikan Islam. Tersedia:

http://dedinoviyanto.wordpress.com/

my-papers/tentang-

pendidikan/konsep-kepuasan-

pelanggan-dalam-manajemen-mutu-

pendidikan-islam/

Moutákis, A., (2004). Quality Assurance

Strategies in Schools A Case Study.

The University of Greenwich School of Education. Tersedia: on line

Tjiptono, F., (1996). Manajemen Jasa. Jogjakarta: Penerbit ANDI.

Wellington, P., (1998).Kaizen Strategies for Cutomer Care. Batam: Interaksara.

Wikipedia. ( ).Quality Assurance.

Tersedia:

(http://en.wikipedia.org/wiki/Quality _assurance) 